\title{
International HTA Experience with Targeted Therapy Approvals for Lung Cancer
}

\author{
Fatma Maraiki ${ }^{1,2,3,4}$ (D) J. Byrnes ${ }^{1} \cdot$ H. Tuffaha ${ }^{1} \cdot$ M. Hinder ${ }^{2,3}$
}

Published online: 3 August 2018

(c) The Author(s) 2018

\begin{abstract}
Objectives The aim of this study was to compare the listing success rates and time incurred to listing of recently approved lung cancer medications across Australia, Canada and England.

Methods A comparison between the three countries was performed with respect to the listing status, time incurred for listing and differences in recommendations made for cost effectiveness. Major uncertainties and limitations that compromise health technology assessment (HTA) recommendations were identified.

Results The listing success rate was found to be low across all three countries (33\% Canada, 17\% England and 8\% Australia). Across the HTA agencies' reviews, comparators were either dissimilar or altered for effectiveness and/or economic analysis. Overall, limited evidence was found for all indications, and uncertainties were identified due to indirect analyses (70\%) and survival extrapolation (100\%). Although most of the indications were concluded to be not cost effective, some were subsequently listed (47\%) at a reduced price and/or with a specific access programme.

Conclusions This study demonstrated a low listing success rate for novel lung therapies internationally within different HTA jurisdictions. Major uncertainties that are resistant to available solutions seem to be common across different countries; thus, international solutions would be beneficial
\end{abstract}

Fatma Maraiki

f_Maraiki@hotmail.com

1 School of Medicine, Griffith University, Brisbane, Australia

2 MSc International Pharmacoeconomics and Health Economics at Hochschule Fresenius, Idstein, Germany

3 Cardiff University, Cardiff, UK

4 Department of Pharmacy, King Faisal Hospital and Research Centre, PO Box 3354, Riyadh 11211, Saudi Arabia

\section{Key Points for Decision Makers}

In the field of cancer, health technology assessment (HTA) evaluations can be restricted due to limited comparative clinical evidence and high cost.

A comparison between three international HTA agencies for novel lung cancer therapy evaluations demonstrated a low listing success rate across Australia, Canada and England.

This analysis identified major uncertainties within the HTA agencies. International solutions may include better use and evaluation of the managed entry schemes and the establishment of international registries.

\section{Introduction}

After cardiovascular disease, cancer is the second most common cause of death globally [1]. In 2013, cancer was responsible for 8.2 million deaths, with 196.3 million years of health life lost due to illness, disability and 
death (DALYs) [2]. Lung cancer remains the leading cause of death among all cancer types. In 2009, the European Union (EU) estimated the cost of cancer care at $€ 126$ billion per annum, with lung cancer causing the most significant economic burden [3]. Of this, only $€ 51$ billion was accounted for by the EU healthcare system, while the remaining $60 \%$ was the result of factors such as loss of productivity and working days, and early death. These data suggest that direct costs should not represent the focus of healthcare policies, as the economic burden extends beyond the boundaries of the healthcare system. Given the above economic concerns, lung cancer in particular is a good case study because of the extensive involvement of personalised medicine in the treatment options.

In the field of cancer, health technology assessment (HTA) evaluations can be restricted due to limited comparative clinical evidence with short-term efficacy results. In addition, the high cost of cancer treatment raises the stakes and may further complicate the HTA appraisal process. For example, early reimbursement for a medication, with undeveloped evidence, may later prove to have only marginal benefit and result in exorbitant opportunity cost. The high uncertainty that can necessitate a lengthy decisionmaking journey may result in delays in patients' access to treatment. In a large international study comparing the success of access to new oncology medicines across five countries (Australia, Canada, England, Germany and France) over a 5-year period [4], new listings were highest in France and Germany, at a similar level in Canada and Australia, and the lowest in England. The mean time from registration to listing was longer for Australia and England than in most other countries. In a similar study, researchers assessed the HTA recommendations for medications used in five cancer sites, including lung cancer, over almost 10 years [5]. Canada had a higher positive recommendation rate (95\%) when compared with the United Kingdom (UK) (48\%). For the former, recommendations were always accompanied by special pricing arrangements.

The recent and rapid development of novel therapies in lung cancer has increased the pressure within HTA agencies around the world. A comparison between the HTA agencies will help to explain the major uncertainties from the agency's perspective and to identify the best natural course for their recommendations. The objective of this study was to compare the listing success rate and time incurred to listing of recently approved lung cancer medications across three countries (Australia, Canada and England), based on HTA documents. Major uncertainties and limiting factors, reported throughout said documents (effectiveness and economic analysis), that compromise HTA recommendations were identified.

\section{Methods}

A stepwise approach was followed. First, the United States Food and Drug Administration (US FDA) databases were reviewed to identify lung cancer medications approved between 2013 and 2016 [6]. Since the first immunotherapy was approved in 2013, this timeframe was considered adequate for the data cut-off in the study. Second, publicly available documents from HTA agencies for the three countries were reviewed. The selected countries were Australia, Canada and England, based on the fact that they use the English language and have wide geographical distribution. The HTA Agencies for these countries are as follows:

- The Pharmaceutical Benefits Advisory Committee (PBAC) in Australia [23].

- The Pan Canadian Oncology Drug Review (pCODR), which can be accessed through The Canadian Agency for Drugs and Technologies in Health (CADTH) website in Canada [28].

- The National Institute of Health and Care Excellence (NICE) in England [35].

The data retrieval cut-off point was September 2016 for the three HTA agencies. A comparison between the three countries was performed, with respect to listing status and differences in recommendations for cost effectiveness. Only initial and final recommendation drafts were reviewed. Other documents, such as the original submissions, were omitted as some were not available online or consistently across the three jurisdictions. Medications that were originally listed in a country before 2013 were excluded from the analysis. The results were analysed and are presented as total figures, owing to the small sample size. The analysis was classified into four major sections to detect key arguments within the summary documents, namely listing success rate; time incurred to access medications; effectiveness and economic analysis; and deferral or rejection recommendations by the HTA agencies' analysis.

\subsection{Listing Success Rate}

For listing status, medications were classified into three categories: first, 'listed', which represents medications recommended by the HTA and reimbursed; second, 'not listed', which indicates medications that are not recommended or are rejected by the HTA; third, 'no submission/under review', which denotes medications that have either had no HTA submission or were pending HTA agency review. The success rate was estimated from the 
total number of listed medications divided by the total number of medications reviewed by the HTA agency for each country.

The analysis also included other information pertinent to the listing process within the country for each medication, including number of submissions, feasibility of the 'priority review process' and the presence of any 'access programme'.

\subsection{Time Incurred to Listing}

To simplify the analysis, the data were classified into three parts: 'time from registration to outcome', 'time from HTA submission to outcome' and 'time from HTA outcome to listing'. However, only the 'time from submission to outcome' data were presented in this analysis because it was considered more pertinent and valuable, as it reflects the actual time required for the HTA review process.

Registration represents the market authorisation, while the HTA's outcome represents the HTA's listing recommendation and the listing represents the actual implementation of 'reimbursement'. Registration dates were obtained from Therapeutic Goods Administration (TGA) in Australia, Health Canada in Canada, and European Medicines Agency (EMA) or Medicines and Healthcare Products Regulatory Agency (MHRA) in England. As MHRA and EMA's approval dates were close, the latter were chosen. In Australia, all submissions to the PBAC were evaluated within the meeting cycles (every 3 months). Accordingly, the date of PBAC submission was assumed to be 3 months before the PBAC meeting cycle, unless specified in the summary documents. Listing date (reimbursement) was obtained from the PBS website for Australia. In Canada, after the positive recommendations for listing, the actual listing process varies between provinces and negotiation on pricing takes place within the pan-Canadian Pharmaceutical Alliance (pCPA); Ontario was selected to represent the actual implementation date. It was noted that in that province, listings were always considered earlier than in other provinces. Despite that, it was selected because it is one of the major provinces for cancer care. In England, while NICE always recommends within 3 months for reimbursement, we were unable to locate an official site with a clear implementation date. The listing dates were therefore obtained from a general web search.

\subsection{Effectiveness and Economic Analysis}

Data collected from effectiveness and economic recommendations were presented as a descriptive analysis. The major points considered were adopted from European Network for Health Technology Assessment (EUnetHTA) recommendations for relative effectiveness assessments (REA) of pharmaceuticals [7]. All captured sources of uncertainty within the summary documents between the nations were standardised to simplify and facilitate the analysis (Table 1).

\subsection{Reasons for Deferral or Rejection of Recommendations by the HTA Agencies' Analysis}

Data were collected from the initial and final recommendations for each medication across the three countries. Medications that were rejected or differed in the initial or final assessments were reviewed to list the main points addressed

Table 1 Examples for the major standardised uncertainties in the effectiveness and economic analysis

\begin{tabular}{|c|c|}
\hline Standardised uncertainties & Example \\
\hline \multicolumn{2}{|l|}{ Effectiveness analysis } \\
\hline Clinical evidence status & Limited or immature evidence \\
\hline Use of indirect comparison & Comparison of clinical results across different interventions \\
\hline Use of response rate as a surrogate marker for survival & In case of absence of progression-free survival (PFS) or overall survival (OS) results \\
\hline Correlation to the country's population/practice & If existing practice has multiple possible comparators or population demographics \\
\hline \multicolumn{2}{|l|}{ Economic analysis } \\
\hline Limited clinical efficacy data & Draw a cost-effectiveness conclusion from limited non-comparative efficacy studies \\
\hline Choice of the economic comparator in submissions & Comparators that were used for the economic analysis \\
\hline Co-dependent technology & Mutation testing status, which includes the role, threshold, listing and screening status \\
\hline Time horizon reconsideration & Truncation of time horizon from 10 to 5 years \\
\hline Extrapolation method & When extrapolating for survival beyond the duration of clinical trials \\
\hline Treatment duration & Treatment duration beyond disease progression \\
\hline Treatment benefit & Extent of treatment benefit beyond cessation of treatment \\
\hline Health utilities or resources estimates & When the value calculated may not reflect those observed values in previous studies \\
\hline Correlation to the country's population/practice & $\begin{array}{l}\text { If practice has multiple choices for comparator such as in Canada, where comparators } \\
\text { may differ across Canadian provinces. Population could be Asian versus non-Asian }\end{array}$ \\
\hline
\end{tabular}


by the HTA for rejections. Data were extracted verbatim from the HTA documents.

\section{Results}

A total of 11 medications, in 12 indications, were identified as recently FDA-approved agents for lung cancer treatment within the last 4 years (Table 2). Two medications (erlotinib and gefitinib) were excluded because they had been listed earlier than 2013 in some of the countries. The final analysis involved 9 medications with 12 indications. The national registration of all indications within the three countries was in line with the FDA approval criteria, except for crizotinib. National registration under TGA in Australia and Health Canada for crizotinib was general for all lines of treatment for patients who are anaplastic lymphoma kinase (ALK) positive. However, the EMA specified the line of therapy in its registration (first- versus second-line therapy) with a 3-year gap in between for each line of therapy. At the time of the HTA agency evaluations, a distinction was also made between first- and second-line therapies for crizotinib, for which separate submissions were required in all three countries.

For all countries, a process existed for a 'priority review process', whereby the submission of a new technology could be performed before, or at the same time as national registration. This process is identified as a 'parallel process' in Australia and as a 'pre-NOC (notice of compliance)' procedure in Canada. A similar system is operated in England. All indications that were approved were reimbursed through an 'access programme' and featured pricing arrangements. It was noted, however, that such an access programme was not specified within the documents in Canada.

\subsection{Listing Success Rate}

Overall, Canada had the highest listing success rate of 33\%, versus 17\% in England and 8\% in Australia at the time of the study (the HTA process was not final for only one submission). In addition, Canada reviewed more indications than the other two countries (six versus three apiece) (Fig. 1). The majority of indications $(\geq 50 \%)$ had not been submitted or were under review by the HTA agencies.

\subsection{Time Incurred to Listing}

Overall, the HTA review process in terms of 'time from submission to outcome' necessitates a lengthy duration of up to 2 years in Australia and England, whereas matters are more timely in Canada, taking up to 1 year. The time required for reimbursement (the 'time from HTA outcome to listing') was a minimum of 3 months for each country.

\subsection{Effectiveness and Economic Analysis}

A summary of the effectiveness and economic recommendations for the submission process is detailed in Tables 3 and 4. The final analysis consisted of seven indications that had HTA submissions. The medications included were afatinib (two indications), crizotinib (three indications), and ceritinib and nivolumab (one indication each).

\subsubsection{Effectiveness Analysis}

Most of the HTA-nominated comparators in the efficacy analysis varied across the agencies for the same technology and indication (Table 3). Different comparators were used for nine of the ten submissions (90\%) across countries for indications that were assessed by at least two nations. It was also noted that even if the technology was submitted within the same time interval, with almost universally accepted international standard practice, the comparators sometimes differed between agencies; for example, regarding the nivolumab and afatinib submissions. Several comparators used were similar to those employed in the registration trials. Most comparators included were considered to be relevant to national or standard disease practice. In submissions that included trials with a comparator arm, eight out of nine ( 90\%) submissions involved additional comparators that differed from those used in the registered trials. For example, in the case of afatinib, epidermal growth factor receptor (EGFR) inhibitors were added to the comparator list, together with chemotherapy; however, only the latter was used as the comparative arm in the registered trials as a standard of care at the time of the study.

The choice of comparators for NICE relied substantially on current clinical practice in England, which included nonlisted technologies or, sometimes, best supportive care as in the case of ceritinib. By contrast, a comparator that is not subsidised by the PBS will not be proposed as a comparator by PBAC in Australia. Finally, a greater number of comparators were selected in Canada due to variations in current accepted practices between Canadian provinces. Afatinib is the best example of how the choice of comparators and final recommendations differed according to funding status in the various Canadian provinces. The final cost-effectiveness decision was different across Canadian provinces according to the choice of the comparator and practice within each province. Consequently, due to discrepancies in comparators between trial data and HTA evaluations across the three countries, analyses were indirect for the efficacy evaluation $(\sim 70 \%)$.

Registration trials that were accepted in the submissions were mostly phase III trials with the primary outcome of survival, either progression-free survival (PFS) or overall survival (OS) $(75 \%)$, or phase I/II trials with no comparator 


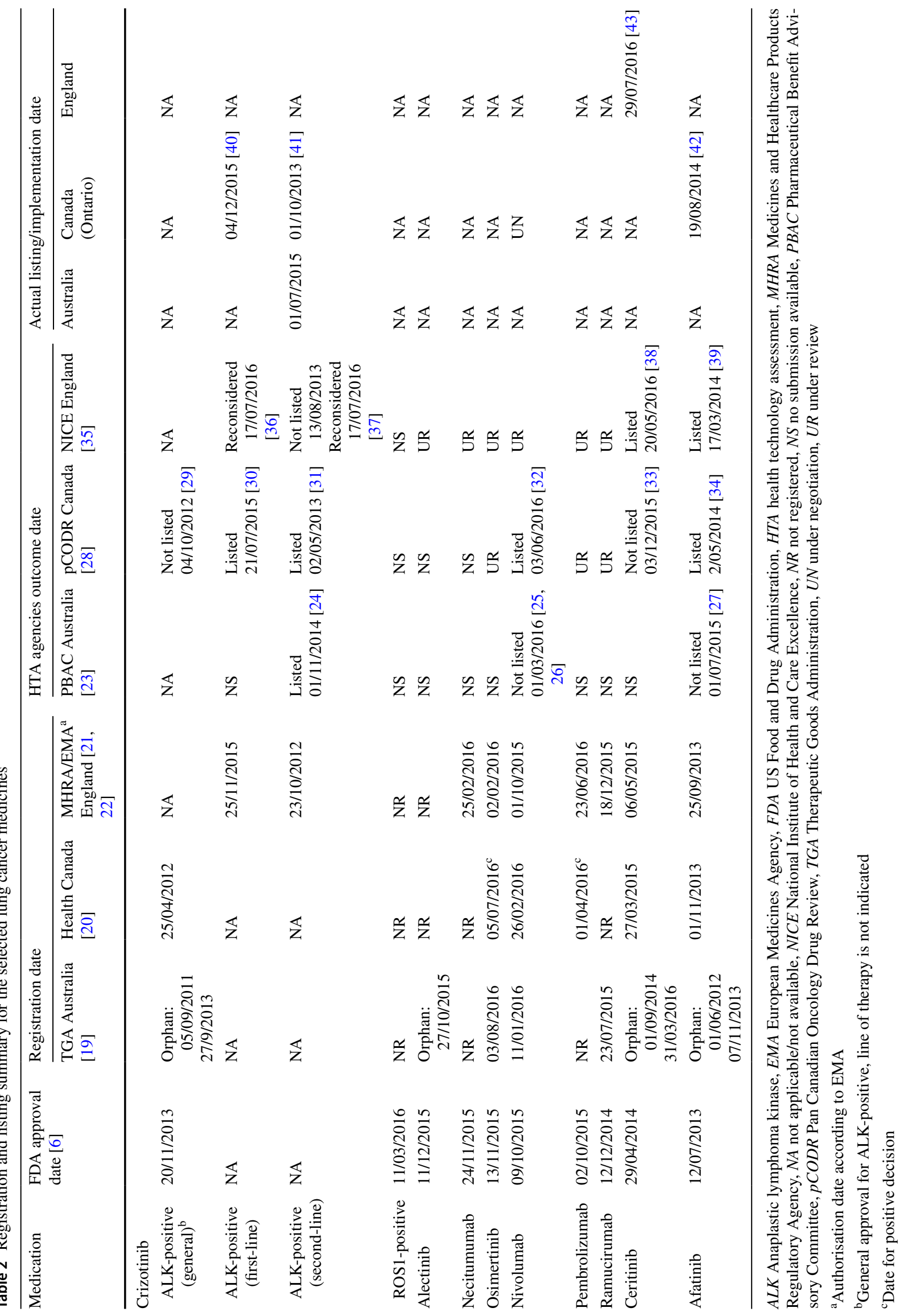




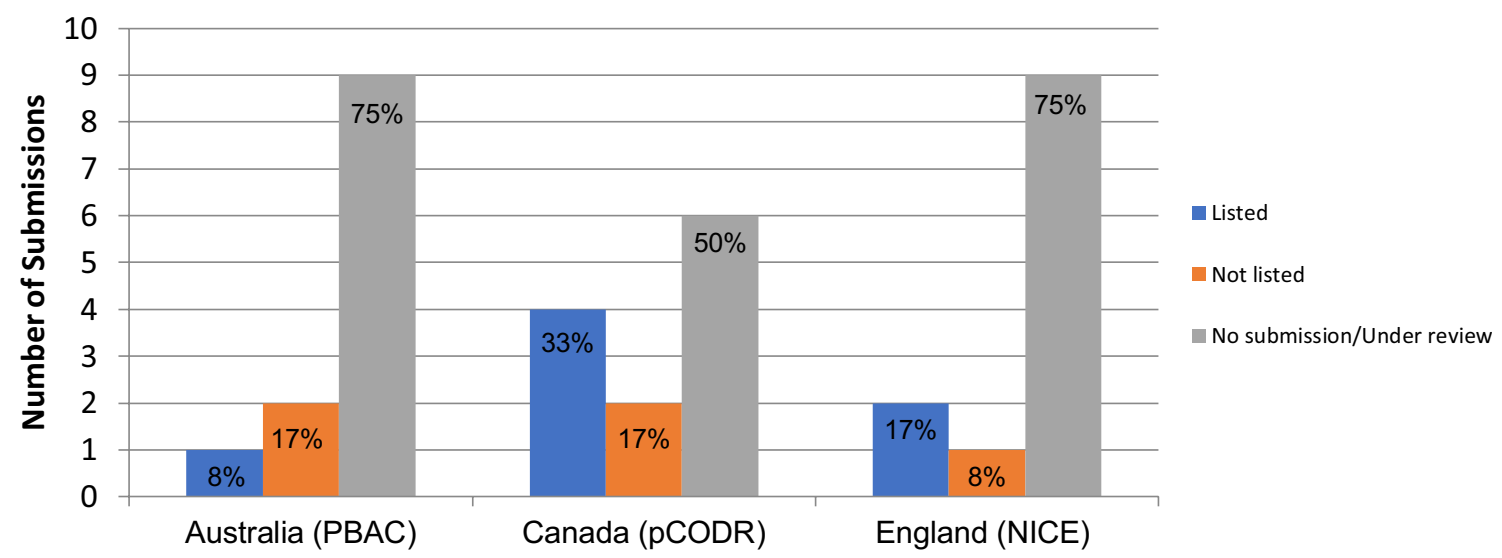

Fig. 1 Listing success rate comparison across countries. PBAC Pharmaceutical Benefit Advisory Committee, $p$ CODR Pan Canadian Oncology Drug Review, NICE National Institute of Health and Care Excellence

arm (25\%). Undeveloped clinical data (including survival, safety or quality of life) in ongoing trials were considered and discussed in all summary documents for future deliberation. Uncertainty regarding the evaluated data related mostly to indirect analysis $(46 \%)$, or limited $(53 \%)$ or immature (38\%) evidence.

Approximately $30 \%$ of the submissions involved uncertainty about the technology's applicability to either the country's population or practice. Another factor associated with uncertainty within the submissions was the use of the disease response rate as a surrogate marker for survival if the early phase I/II trials had been accepted with no comparator arm. Only one out of three submissions were recommended and listed by the HTA with no comparator arm or survival evidence; namely, the NICE evaluation for ceritinib.

\subsubsection{Economic Analysis}

Comparators used for economic evaluations (Table 4), among others nominated for the efficacy assessment, were limited to the current national listed/reimbursed alternatives used for the same indication. For example, in Canada, erlotinib and gefitinib were nominated as a comparison against the effectiveness of afatinib; however, only gefitinib was included in the economic analysis because erlotinib was not funded as a first-line therapy at the time of evaluation.

Survival extrapolations for the economic evaluation were applied $(\sim 100 \%)$ to all evaluated submissions in this study. Of the 13 submissions, eight (62\%) had a horizon of $>5$ years, three $(23 \%)$ used a 5 -year horizon and two were not reported $(15 \%)$. All submissions that used a horizon of $>5$ years in their economic analysis were reconsidered and readjusted by the HTA agency, except for submissions to NICE. In general, the incremental cost-effectiveness ratio (ICER) was required to be recalculated by the HTA agencies in most of the cases. When that was done, the new ICER was always higher (14 of the 15 economic analyses, 95\%) than that proposed by the company in the initial submission.

The final decisions on cost effectiveness taken by the agencies could not be determined in three of the $15(20 \%)$ economic analyses for different comparators within submissions. Indications were considered cost effective in only two of the 15 analyses (13\%), cost effective at a reduced price or within a special programme in seven of the $15(47 \%)$ and not cost effective in three of the $15(20 \%)$. Of the 13 submissions, uncertainty was identified in relation to extrapolation methods in 13 (100\%), health utility estimates in seven (54\%), co-dependent technologies in five (38\%), relation to country practice or population in four $(30 \%)$, treatment benefit in four (30\%), treatment duration in three (23\%) and resource estimation in two (15\%). In the submitted analyses, uncertainty identified by the agency in relation to the choice of comparators pertained either to missing data or dropouts, as represented in three of the 13 submissions (23\%).

\subsection{Deferral or Rejection of Recommendations by the HTA Agencies' Analyses}

In Table 5, major similarities were identified across HTA agencies and indications. There was uncertainty regarding the clinical evidence due to immature or limited data, together with unresolved discussions (such as limitations, uncertainties and draw backs) on ongoing trials. NICE was the only agency that proposed a future review, regardless of the final recommendations. Reviews were considered in terms of the updated clinical data and for regulatory and access situations. For example, where crizotinib was earlier rejected by NICE, ceritinib was later approved for ALKpositive non-small cell lung cancer (NSCLC) in patients who failed crizotinib. The latter was not available within the NHS at that time and is currently administered through the Cancer Drugs Fund. Therefore, there was a subsequent 


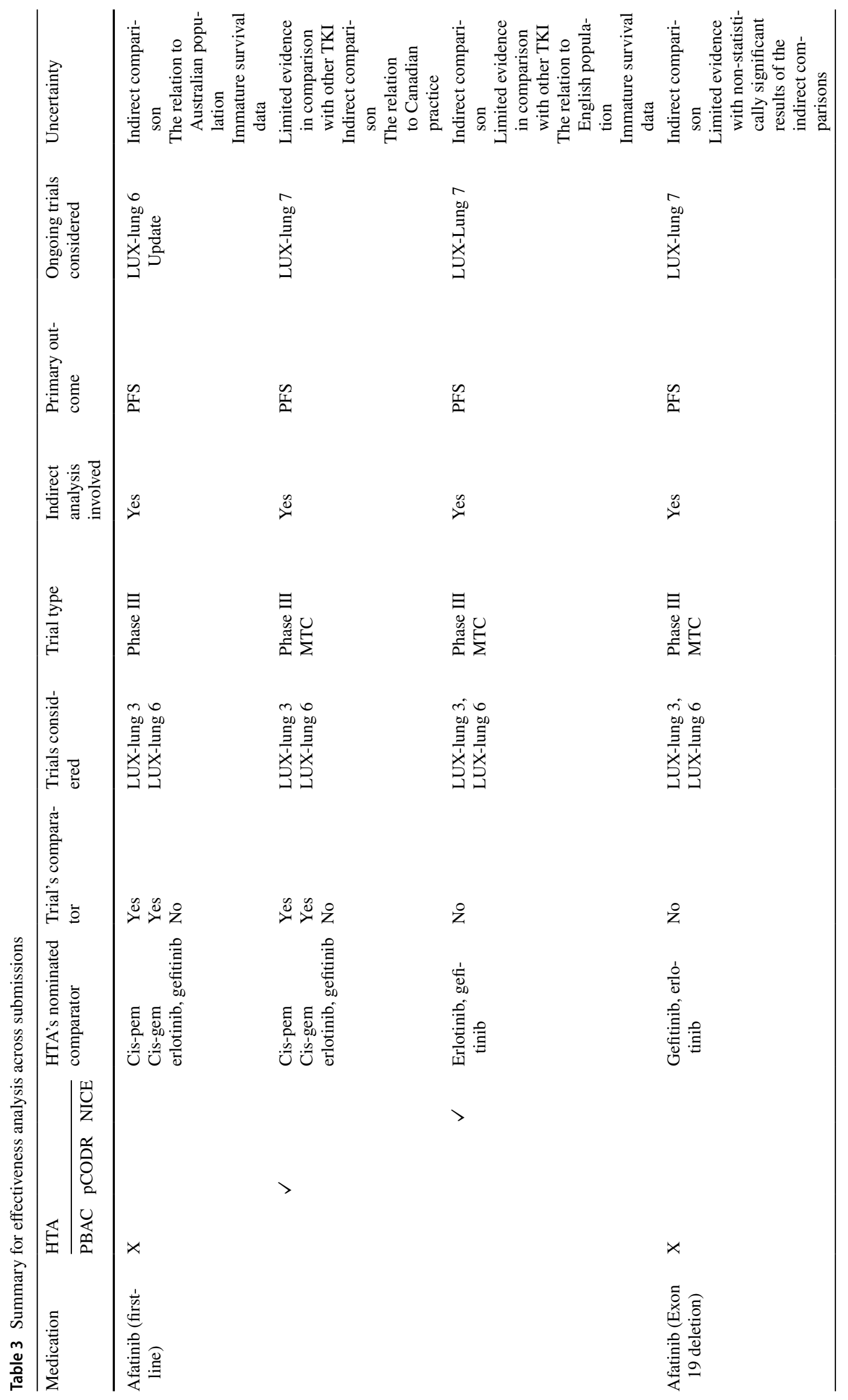




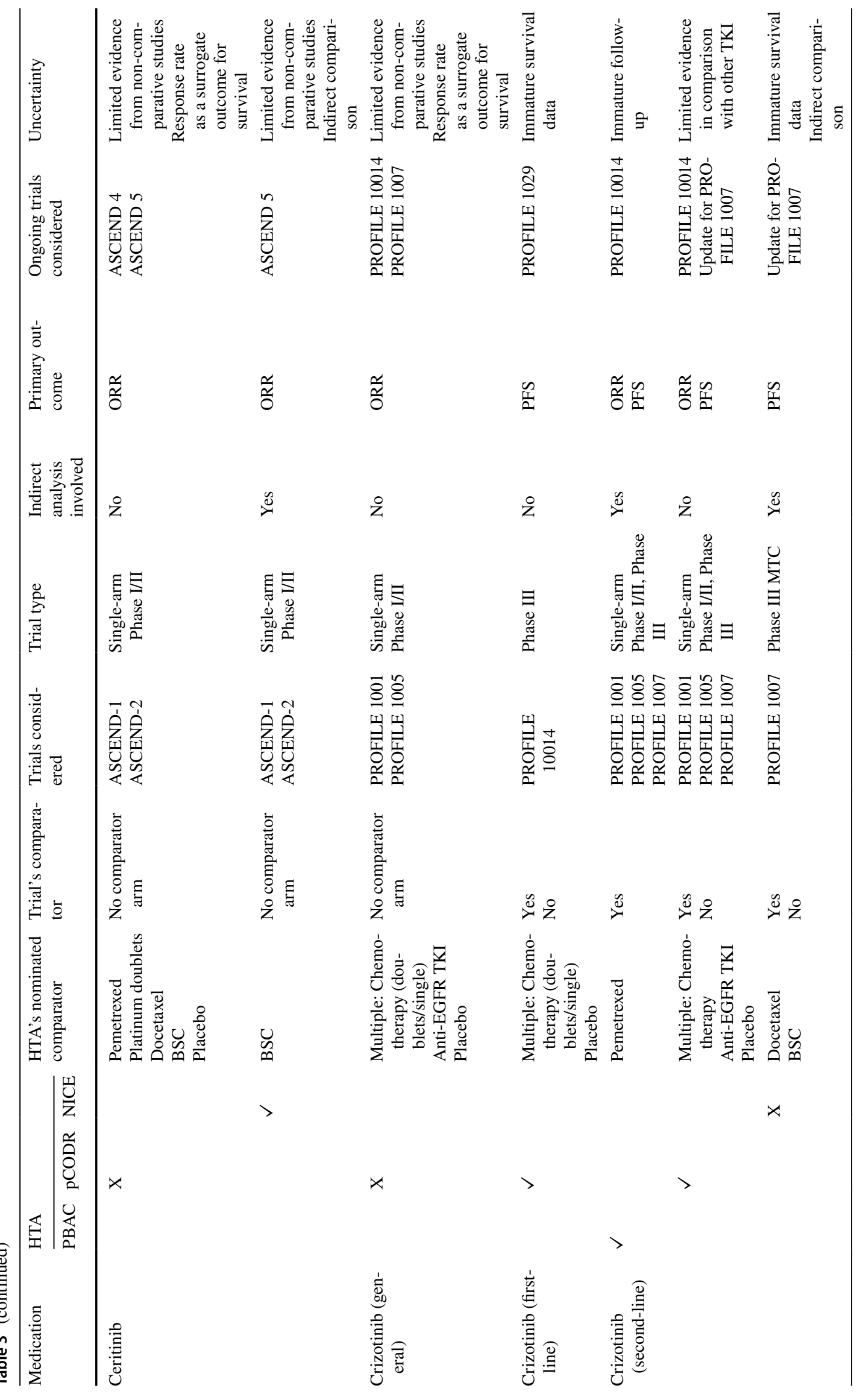




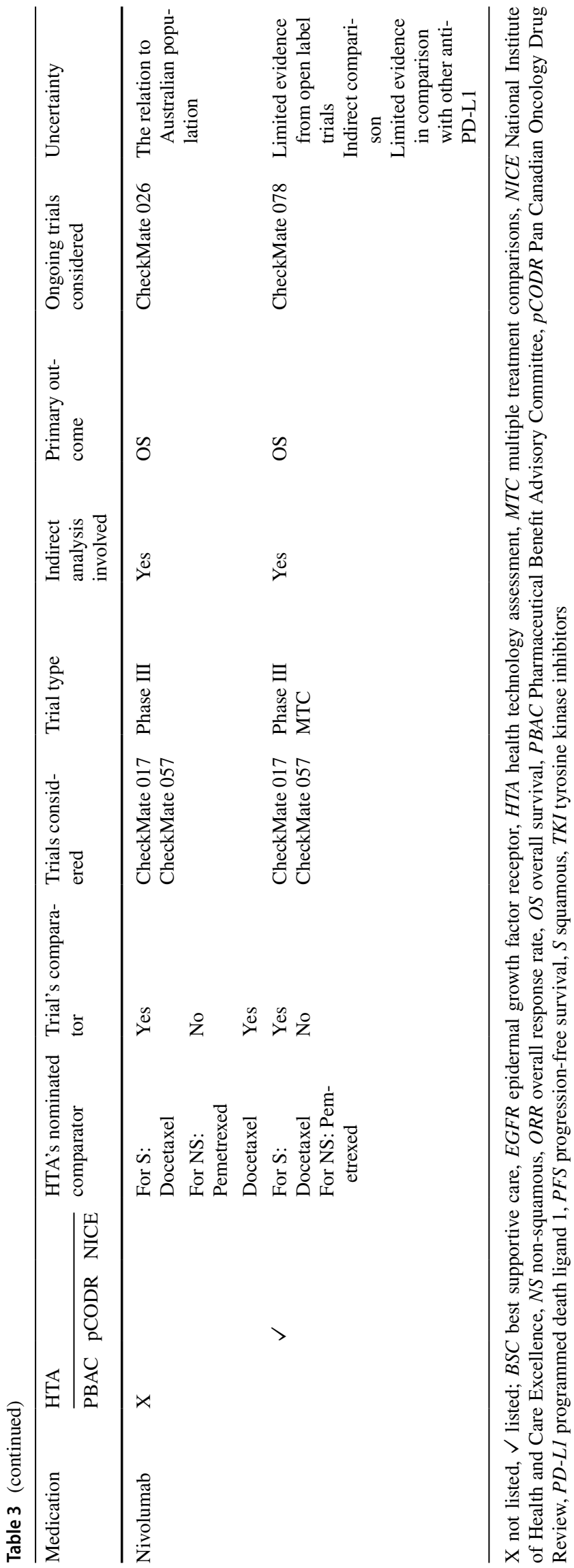

review of ceritinib, after its approval was proposed by NICE, for when crizotinib is no longer managed by said Fund.

Other major points related to mutation testing as a codependent technology. The uncertainty around the initial cost-effectiveness decision for the indications evaluated constituted the major obstacle to its listing. Finally, cost effectiveness was always considered in terms of the provision of a discount or price reduction. Usually, a medication is recommended in conjunction with the use of a risk-sharing arrangement, like the managed entry scheme (MES) in Australia or the patient access scheme (PAS) in England.

Minor differences related to the regulatory processes or treatment guidelines within each country, as was the case with afatinib. The main issue with the initial submission of this drug in Australia was that the requested indication was outside the TGA-approved indication. However, the requested restriction was not consistent with the national and international guideline recommendations for the second submission.

\section{Discussion}

The listing success rate for lung cancer treatment, as a reference case, was found to be low across all three countries under investigation: 33\% for Canada, 17\% for England and $8 \%$ for Australia. This means that more than half of the technologies had no HTA submission yet or were under review by the HTA agencies at the time of this review. In general, Canada was further ahead in the listings rate and numbers of submissions appraised, and has a shorter HTA review process of $<1$ year, compared with Australia and England. All three countries have a priority review process whereby the HTA submission could be performed at the same time as national registration. Within the effectiveness analysis, $90 \%$ of submissions involved additional comparators that differed from those used in the registered trials. Across the HTA agencies' reviews, comparators were either dissimilar or altered for effectiveness and/or economic analysis for the same indication. Overall, immature or limited evidence was apparent for all indications, and uncertainties formed due to indirect analyses (70\%) and survival extrapolation (100\%). Within the economic evaluation, a readjusted time horizon and recalculated ICER were frequently proposed by the HTA agencies in all three countries. The submitted time horizon was usually $>5$ years $(62 \%)$, while the newly recalculated ICER was invariably higher $(95 \%)$ than that proposed by the drug company. Final recommendations for NICE are consistently accompanied by a future review for evidence and regulatory access updates. Despite most of the indications being deemed not cost effective, they were subsequently listed (47\%) at a reduced price and/or with a country companion-specific access programme. In addition, 


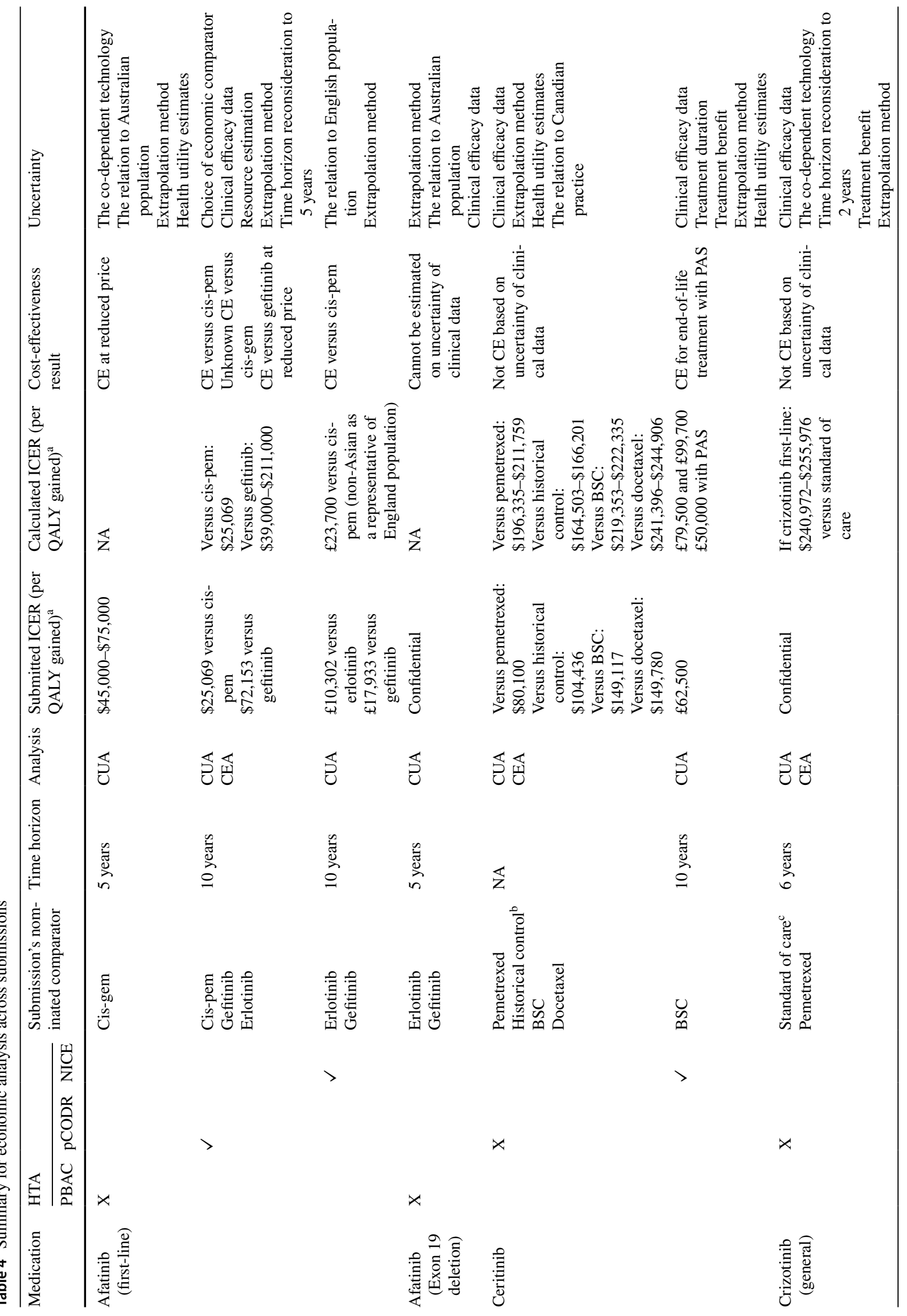




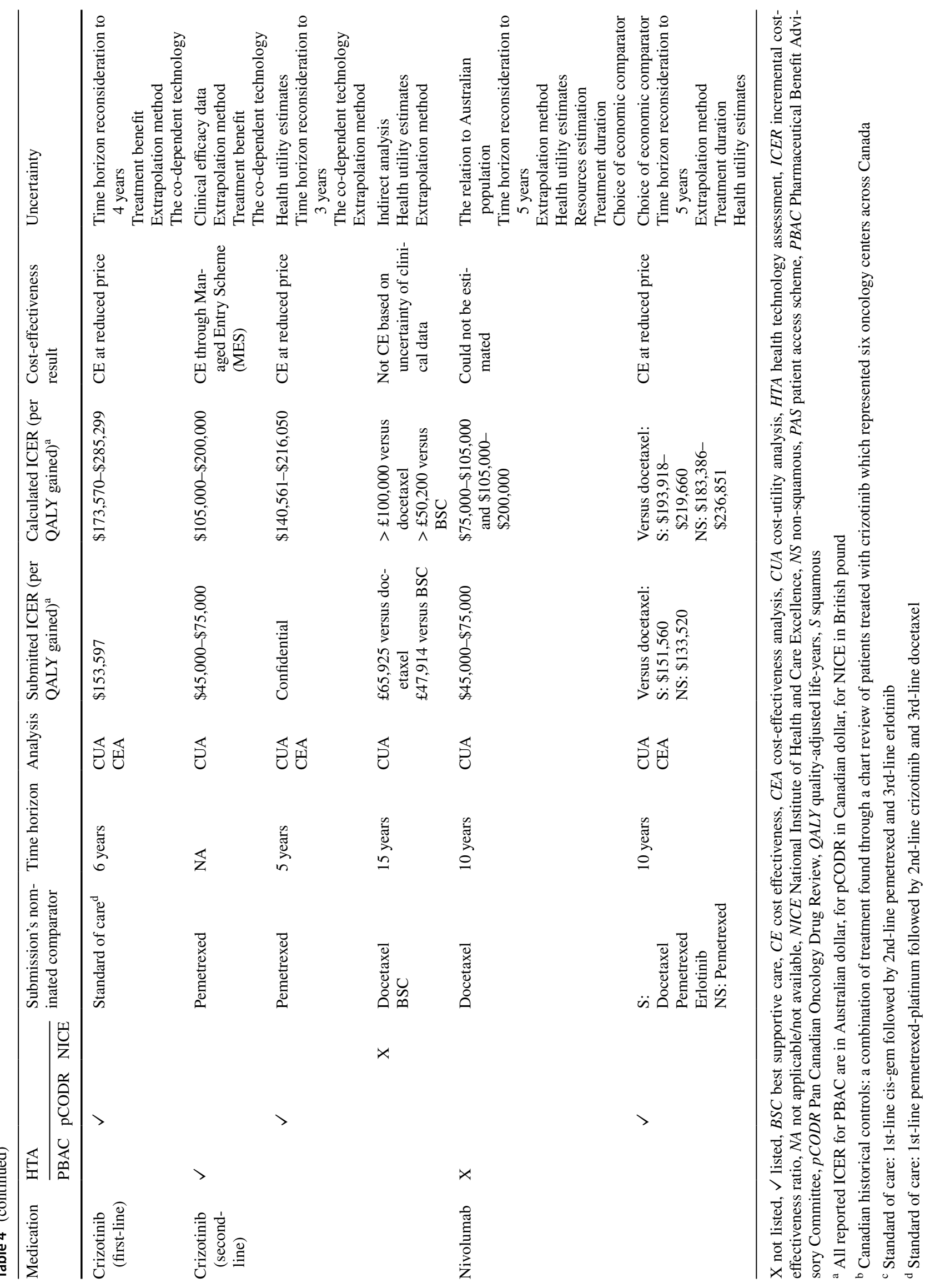


the status of national mutation test listing was a common theme for the initial recommendations by all HTAs. Despite the small size of this study, a similar analysis demonstrated higher positive recommendations for oncology drugs by Canada when compared with the UK [5].

Within this study, indirect analysis and extrapolation created substantial uncertainties surrounding the efficacy and economic evidence. The approval of medications based on preliminary clinical evidence is clearly more prominent in cancer than in other specialties. These common inherited uncertainties in the cancer field are bound to persist and place pressure on stakeholders. The 'trade-off' is geared towards early access with a consideration of evidence development, which, in broad terms, is not the case in this analysis [8]. It was observed that more rejections and deferrals for technologies were seen than accepting with an access program.

A variety of global regulatory mechanisms have been introduced to overcome these uncertainties. First, to expedite registrations for treatment of diseases with unmet medical needs, early registration of innovative medicines was launched by several market-authorisation agencies, such as Breakthrough Therapy Designation (BTD) by the FDA in 2012 and PRIority Medicine (PRIME) by the EMA in 2016 $[9,10]$. In this analysis, registration status seemed to have an implication in delaying access, irrespective of the currently available priority review processes. Afatinib, for example, had three unsuccessful submissions for listing in Australia, as a result of a wide range of national registration matters, including TGA-proposed indication and status of the TGA application.

Emerging schemes include performance-based risksharing arrangements for early access, which support the concept of providing additional benefit and value for money or 'coverage with evidence development' (CED) [11]. These schemes may better serve the HTA agencies by sharing the financial risk owing to clinical uncertainty with the manufacturer. These agreements have been widely accepted under a variety of names across countries. The programmes linked to this study include the MES as a risk-sharing arrangement (RSA) in Australia and the PAS in the England. Canada has no such programs but has a different scenario, namely the NOC/c (notice of compliance with conditions), while a more recent development is 'Vanessa's Law' in 2013 [12]. In respect to each specific programme, there are several measures mandated for their establishment. This was recently debated by several countries, including Canada [13]. Some general measures, such as a data collection plan (registry), electronic health records (EHRs), a design and enforce discount, and an authority and ability to de-list, have all been nominated. Europe, for example, launched the 'Get Real' project in 2013 to collect and synthesise real-world evidence (RWE), which could be adopted earlier in pharmaceutical research and development (R\&D) and the healthcare decision-making process [14]. However, an estimation of the impact of these access programmes on HTAs requires further evidence of their effectiveness.

In general, in this study, HTAs mostly identified a higher ICER than that submitted by the company and subsequently requested a price reduction regardless of implementing RSA. It would appear that negotiation strategies of companies to initially request a high medication price may contribute to the delay in patient access. As such, HTA agencies could further consider mechanisms that encourage companies to offer a lower price earlier in the HTA process to enhance early patient access.

The HTA agency's selection of comparators will influence the ICER and, subsequently, the cost-effectiveness recommendations. Time is a very sensitive factor in deciding comparators in cancer treatments, where registered comparative studies have a comparator arm that might not be the standard of care at the time of subsequent HTA evaluation. As in the case of afatinib, the registered studies used a chemotherapy doublet as a comparator, while erlotinib and gefitinib were nominated by the agencies as the standard of care for patient treatment with EGFR mutation. In addition, matters are more uncertain for medications used in palliative settings, where the registered trial has no comparator arm. Accordingly, it is a challenge for the drug company to identify the comparator in the technology submission, and it may further encounter uncertainty for the comparator nominated by the HTA's reviewers. The comparator choice is influenced by multiple factors, which could include ethical, social or even equity dilemmas, as in the case of ceritinib. The situation may not be the same for drugs other than antineoplastics, as shown in various studies where comparators were found to be similar for Australia and Canada for 25 products reviewed, of which only two were cancer medications [15].

When one study compared market access for lung cancer medications, access to biomarker testing was one of the major limitations when it came to comparing the performance of Canada and Latin America [16]. This was also, informally, one of the reasons for delaying the listing of medications across the three countries assessed in this study. Some of these tests are not yet settled internationally, with concerns over the comparability of various assays, which will consequently compromise access at the national level. One of the latest examples is the PD-L1 (programmed death ligand 1) immunostaining test, which has different thresholds and target cells (i.e. tumour cells, immuno-infiltrating cells). Pembrolizumab, in frontline treatment for NSCLC, has just been published as having a survival benefit in PDL1-positive patients [17]. This was forecast to be the next standard of care with the adoption of the PD-L1 screening practice by many experts. Given the complexities of biomarker testing as a companion diagnostic, a 'blueprint 
Table 5 Overview of submissions' deferral/rejection recommendations

\begin{tabular}{|c|c|c|c|}
\hline Medications & PBAC (Australia) & pERC (Canada) & NICE (England) \\
\hline Afatinib & $\begin{array}{l}\text { First submission (second/third-line): } \\
\text { Requested listing was outside the TGA } \\
\text { indication } \\
\text { Unaccepted economic approach due to } \\
\text { the weakness of the clinical claim } \\
\text { Second submission (first-line): } \\
\text { Not cost effective, request for Risk Share } \\
\text { Arrangement (RSA) } \\
\text { Third submission (first-line with restric- } \\
\text { tion for exon } 19 \text { deletion): } \\
\text { Rejected due to inadequate evidence } \\
\text { The restricted indication to exon } 19 \text { is } \\
\text { not consistent with previous PBAC, US } \\
\text { guidelines }\end{array}$ & $\begin{array}{l}\text { Initial recommendations: } \\
\text { Uncertainty in clinical benefit and cost } \\
\text { effectiveness compared with other } \\
\text { EGFR inhibitors } \\
\text { Waiting for the ongoing comparative } \\
\text { LUX-Lung } 7 \text { trial } \\
\text { Final recommendations: } \\
\text { Recommended but not for all Canadian } \\
\text { provinces because of different cost- } \\
\text { effectiveness decisions }\end{array}$ & \\
\hline Ceritinib & & $\begin{array}{l}\text { Initial and final recommendations: } \\
\text { Not recommended because of limited } \\
\text { evidence } \\
\text { Waiting for ongoing (phase III) } \\
\text { ASCEND } 4 \text { and ASCEND } 5 \text { trials }\end{array}$ & $\begin{array}{l}\text { Final appraisal 1: } \\
\text { Not recommended because of limited } \\
\text { evidence } \\
\text { Not cost effective with high ICER } \\
\text { Waiting for ongoing (phase III) ASCEND } \\
5 \text { trial } \\
\text { Final appraisal 2: } \\
\text { Recommended with discount agreed in the } \\
\text { patient access scheme (PAS) }\end{array}$ \\
\hline Crizotinib & $\begin{array}{l}\text { First submission (second-line): } \\
\text { Deferred twice for price reduction to } \\
\text { achieve an acceptable cost-effectiveness } \\
\text { ICER } \\
\text { Immature survival data from PROFILE } \\
1007 \text { trial } \\
\text { Final submission (second-line): } \\
\text { Recommended through managed entry } \\
\text { scheme (MES) } \\
\text { List ALK mutation testing }\end{array}$ & $\begin{array}{l}\text { First submission (general indication): } \\
\text { Not recommended because of limited } \\
\text { evidence } \\
\text { Unable to estimate cost effectiveness } \\
\text { Uncertainty around ALK-testing screen- } \\
\text { ing cost } \\
\text { Waiting for ongoing trials PROFILE } \\
\text { 1007/10014 } \\
\text { Resubmission recommendations: } \\
\text { Recommended with two separate sub- } \\
\text { missions for ALK-positive (first-line } \\
\text { and second-line therapy) } \\
\text { Establish a routine ALK mutation test- } \\
\text { ing }\end{array}$ & $\begin{array}{l}\text { Final appraisal (second-line): } \\
\text { Not recommended as it is not cost-effec- } \\
\text { tive } \\
\text { Immature survival data from PROFILE } \\
1007 \text { trial and the impact of crossover } \\
\text { design in the study } \\
\text { The access and cost of ALK testing in the } \\
\text { UK }\end{array}$ \\
\hline Nivolumab & $\begin{array}{l}\text { First submission: } \\
\text { Economic analysis was not adequately } \\
\text { demonstrated } \\
\text { Requested more restriction inclusion } \\
\text { criteria } \\
\text { Status of PD-L1 testing in Australia } \\
\text { Advice for financial cap due to uncer- } \\
\text { tainty of the estimated net cost }\end{array}$ & & \\
\hline
\end{tabular}

$A L K$ Anaplastic lymphoma kinase, EGFR epidermal growth factor receptors, ICER incremental cost-effectiveness ratio, NICE National Institute of Health and Care Excellence, PBAC Pharmaceutical Benefit Advisory Committee, PD-L1 programmed death ligand 1, $p E R C$ Pan-Canadian Oncology Drug Review (pCODR) Expert Review Committee, TGA Therapeutic Goods Administration

proposal' is now being developed by the pharmaceutical and diagnostic companies to establish an evidence-based diagnostic characteristic for PD-L1 [18]. As such, a potential aid will further facilitate countrywide access to these tests as a predictive biomarker for the new medications.

A limitation of the analysis is that the analysis was performed on lung cancer medications and cannot be extrapolated to other disease sites. Also, the analysis was limited to only three countries, but there are other HTA agencies that review cancer drugs.

\section{Conclusion}

This analysis demonstrated a low listing success rate for novel lung cancer therapies internationally within different HTA jurisdictions. Major uncertainties that are resistant to 
available solutions, such as managed access programmes, seem to be common across different countries. International solutions for major uncertainties may include better use and evaluation of managed entry schemes currently in play and/ or further research into the design of better schemes. In addition, international collaboration among HTA agencies to establish data collection strategies will enhance larger and potentially more valuable registries.

Acknowledgements This project was performed in partial fulfilment of the requirement of Cardiff University for the degree of MSc in International Pharmacoeconomics and Health Economics, a degree awarded by Cardiff University delivered at Hochschule Fresenius University of Applied Sciences, Idstein, Germany. The authors thanks Cardiff University for providing continuous support to the Masters program of International Pharmacoeconomics and Health Economics. The authors are grateful to Prof. Paul Scuffham for accepting this Masters research at the Centre for Applied Health Economics (CAHE) in Griffith University, Brisbane, Australia.

Authors' Contribution All authors (F. Maraiki, J. Byrnes, H. Tuffaha, $M$. Hinder) contributed to the design of the study, review of the study search protocol, analysis and interpretation of the results, and writing and review of the manuscript.

Data Availability Statement All data generated or analysed during this study are included in this published article (figure/tables)

\section{Compliance with Ethical Standards}

Conflict of interest Doctors J. Byrnes and H. Tuffaha are researchers at the Centre for Applied Health Economics (CAHE) in Griffith University, Brisbane, Australia. The research was performed by F. Maraiki in the MSc program at Welsh School of Pharmacy, Cardiff University, UK. Prof. M. Hinder was academic tutor for the MSc thesis. JB, HT, and FM have no financial involvement with any organisation or entity with a financial interest in or financial conflict with the subject matter or materials discussed in the manuscript. $\mathrm{MH}$ is an employee of Novartis, Basel, Switzerland.

Funding This paper was not funded.

Open Access This article is distributed under the terms of the Creative Commons Attribution-NonCommercial 4.0 International License (http://creativecommons.org/licenses/by-nc/4.0/), which permits any noncommercial use, distribution, and reproduction in any medium, provided you give appropriate credit to the original author(s) and the source, provide a link to the Creative Commons license, and indicate if changes were made.

\section{References}

1. Abubakar II, Tillmann T, Banerjee A. Global, regional, and national age-sex specific all-cause and cause-specific mortality for 240 causes of death, 1990-2013: a systematic analysis for the Global Burden of Disease Study 2013. Lancet. 2015;385(9963):117-71.

2. Fitzmaurice C, Dicker D, Pain A, et al. The global burden of cancer 2013. JAMA Oncol. 2015;1(4):505-27.
3. Luengo-Fernandez R, Leal J, Gray A, et al. Economic burden of cancer across the European Union: a population-based cost analysis. Lancet Oncol. 2013;14(12):1165-74.

4. Wonder M-Wonder Drug Consulting Pty LTD. Report prepared for the medicines Australia Oncology Industry Task Force. Reimbursement success rates and timeline for new medicines for cancer; an international comparison. http://www.medic inesaustralia.com.au/files/2013/07/140323_OIT_Wonder-Repor t_FINAL.pdf. Accessed 04 Dec 2016.

5. Chabot I, Rocchi A. Oncology drug health technology assessment recommendations: Canadian versus UK experiences. ClinicoEconomics Outcomes Res CEOR. 2014;6:357.

6. FDA, Food \& Drug Administration. Hematology/oncology (cancer) approvals and safety notifications. http://www.fda.gov/ Drugs/InformationOnDrugs/ApprovedDrugs/ucm279174.htm. Accessed 10 Nov 2016.

7. Kleijnen S, Goettsch W, d'Andon A. et al. European network for health technology assessment (EunetHTA) JA WP5: relative effectiveness assessment (REA) of pharmaceuticals. https ://eunethta.fedimbo.belgium.be/sites/5026.fedimbo.belgium.be/ files/Final\%20version $\% 20$ of $\% 20$ Background $\% 20$ Review $\% 20$ on $\% 20$ Relative $\% 20$ Effectiveness $\% 20$ Assessment $\% 2$ Bappendix .pdf. Accessed 30 Nov 2016.

8. Woodcock J. Evidence vs. access: can twenty-first-century drug regulation refine the tradeoffs? Clin Pharmacol Ther. 2012;91(3):378-80.

9. FDA, Food and Drug Administration. Guidance for industry. Expedited programs for serious conditions-drugs and biologics. http://www.fda.gov/downloads/drugs/guidancecomplia nceregulatoryinformation/guidances/ucm358301.pdf. Accessed 30 Nov 2016.

10. EMA, European Medicines Agencies. PRIME: priority medicines. http://www.ema.europa.eu/ema/index.jsp\%3Fcurl\%3Dpag es/regulation/general/general_content_000660.jsp\%26mid \%3DWC0b01ac058096f643. Accessed 26 Oct 2016.

11. Garrison LP, Towse A, Briggs A, et al. Performance-based risksharing arrangements - good practices for design, implementation, and evaluation: report of the ISPOR good practices for performance-based risk-sharing arrangements task force. Value Health. 2013;16(5):703-19.

12. Health Canada. 2016. Protecting Canadians from unsafe drug act (Vanessa's Law): amendments to the food and drugs act (Bill C-17). http://www.hc-sc.gc.ca/dhp-mps/legislation/unsafedrug s-droguesdangereuses-eng.php. Accessed 26 Oct 2016.

13. Cole A, Chan A, Mujoomdar M. et al. How can HTA in the Asia-Pacific area respond to increased clinical uncertainty? In: Report of the HTAi 2016 Panel Session, 10-14 May 2016, Tokyo. https://www.ohe.org/publications/how-can-health-techn ology-assessments-asia-pacific-area-respond-increased-clinical. Accessed 04 Dec 2016.

14. GetReal. IMI GetReal. https://www.imi-getreal.eu. Accessed 30 Nov 2016.

15. Abs, Australian Bureau of Statistics. 2016. Causes of death, Australia, 2015. http://www.abs.gov.au/ausstats/abs\%40.nsf/ mediareleasesbyCatalogue/5A3ACB70838C1ED7CA25803B0 01801FC?OpenDocument. Accessed 04 Dec 2016.

16. Lopes G, Arrieta O, Bonelli P, et al. High-cost oncologic medication access: why is Latin America falling behind? case study in non-small cell lung cancer (NSCLC). Value Health. 2015;18(7):A825.

17. Reck M, Rodríguez-Abreu D, Robinson AG, et al. Pembrolizumab versus chemotherapy for PD-L1-positive non-small-cell lung cancer. N Engl J Med. 2016;375:1823-33.

18. American Association for Cancer Research (AACR). A blueprint proposal for companion diagnostic comparability. https ://www.aacr.org/AdvocacyPolicy/GovernmentAffairs/Docum 
ents/FDA-AACR-ASCO-Complexities-in-Personalized-Medic ine-Blueprint-Proposal.pdf. Accessed 15 Jul 2018.

19. Australian Government. Department of Health Therapeutic Goods administration (TGA). https://www.tga.gov.au/. Accessed 27 Oct 2017.

20. Government of Canada. https://www.canada.ca/en/health-canad a.html/. Accessed 27 Oct 2017

21. GOV.UK. Medicines \& Healthcare Products Regulatory Agency (MHRA). https://www.gov.uk/government/organisations/medic ines-and-healthcare-products-regulatory-agency. Accessed 27 Oct 2017.

22. European Medicines Agency (EMA) Science medicines health. http://www.ema.europa.eu/ema/. Accessed 27 Oct 2017.

23. Australian Government. Department of health. The pharmaceutical benefit scheme (PBS). Public summary documents by product. http://www.pbs.gov.au/info/industry/listing/elements/pbac-meeti ngs/psd/public-summary-documents-by-product. Accessed 27 Oct 2017.

24. Australian Government. Department of Health. The pharmaceutical benefit scheme (PBS). Public summary documents by product. http://www.pbs.gov.au/industry/listing/elements/pbac-meetings/ psd/2014-11/files/crizotinib-psd-11-2014.pdf. Accessed 27 Oct 2017.

25. Australian Government. Department of Health. The pharmaceutical benefit scheme (PBS). Public summary documents by product. http://www.pbs.gov.au/industry/listing/elements/pbac-meetings/ psd/2016-03/files/nivolumab-non-squamous-psd-march-2016.pdf. Accessed 27 Oct 2017.

26. Australian Government. Department of Health. The Pharmaceutical Benefit Scheme (PBS). Public Summary Documents by Product. http://www.pbs.gov.au/industry/listing/elements/pbac-meeti ngs/psd/2016-03/files/nivolumab-squamous-psd-march-2016.pdf. Accessed 27 Oct 2017.

27. Australian Government. Department of Health. The Pharmaceutical Benefit Scheme (PBS). Public Summary Documents by Product. http://www.pbs.gov.au/industry/listing/elements/pbac-meeti ngs/psd/2015-07/files/afatinib-psd-july-2015.pdf. Accessed 27 Oct 2017.

28. CADTH evidence Driven. https://www.cadth.ca/. Accessed 27 Oct 2017.

29. CADTH evidence Driven. https://www.cadth.ca/sites/default/files /pcodr/pcodr-xalkorinsclc-fn-rec.pdf. Accessed 27 Oct 2017.
30. CADTH evidence Driven. https://www.cadth.ca/sites/default/files /pcodr/pcodr_xalkori_1stln_nsclc_fn_rec.pdf. Accessed Oct 27 2017.

31. CADTH evidence Driven. https://www.cadth.ca/sites/default/files /pcodr/pcodr-xalkoriresub-fn-rec.pdf. Accessed 27 Oct 2017.

32. CADTH evidence Driven. https://www.cadth.ca/sites/default/files /pcodr/nivolumab_opdivo_nsclc_fn_rec.pdf. Accessed 27 Oct 2017.

33. CADTH evidence Driven. https://www.cadth.ca/sites/default/files /pcodr/pcodr_ceritinib_zykadia_nsclc_fn_rec.pdf. Accessed 27 Oct 2017.

34. CADTH evidence Driven. https://www.cadth.ca/sites/default/files /pcodr/pcodr-giotrif-nsclc-fn-rec.pdf. Accessed 27 Oct 2017.

35. National Institute for Health and Care Excellence (NICE). https ://www.nice.org.uk/. Accessed 27 Oct 2017.

36. National Institute for Health and Care Excellence (NICE). https ://www.nice.org.uk/guidance/ta406/resources/crizotinib-for-untre ated-anaplastic-lymphoma-kinasepositive-advanced-nonsmallce 1l-lung-cancer-pdf-82604546118853. Accessed 27 Oct 2017.

37. National Institute for Health and Care Excellence (NICE). https ://www.nice.org.uk/guidance/ta422/resources/crizotinib-for-previ ously-treated-anaplastic-lymphoma-kinasepositive-advancednonsmallcell-lung-cancer-pdf-82604660332741. Accessed 27 Oct 2017.

38. National Institute for Health and Care Excellence (NICE). https:// www.nice.org.uk/guidance/ta395/documents/final-appraisal-deter mination-document-2. Accessed 27 Oct 2017.

39. National Institute for Health and Care Excellence (NICE). https ://www.nice.org.uk/guidance/ta310/documents/lung-cancer-nonsmall-cell-egfr-mutation-positive-afatinib-final-appraisal-deter mination-document2. Accessed 27 Oct 2017.

40. CADTH evidence Driven. https://www.cadth.ca/sites/default/files /pcodr/pcodr-provfund_xalkori_nsclc1stline.pdf. Accessed 27 Oct 2017.

41. CADTH evidence Driven. https://www.cadth.ca/sites/default/files/ pcodr/pcodr-provfund_xalkorire-nsclc.pdf. Accessed 27 Oct 2017.

42. CADTH evidence Driven. https://www.cadth.ca/sites/default/files /pcodr/pcodr-provfund_giotrif-nsclc.pdf. Accessed 27 Oct 2017.

43. NHS England. Cancer Drug Fund. https://www.england.nhs.uk/ cancer/cdf/. Accessed 27 Oct 2017. 